\title{
PCR Cloning and Partial Sequencing of rtxA Gene of non-O1 / non-O139 Vibrio cholerae Isolated from Gold Fish Carassius auratus in India.
}

\author{
T. RAJA SWAMINATHAN ${ }^{*}$, NEERAJ SOOD ${ }^{2}$, GAURAV RATHORE ${ }^{2}$ \\ REHANA ABIDI ${ }^{2}$ and W. S. LAKRA ${ }^{2}$ \\ ${ }^{1}$ National Bureau of Fish Genetic Resources Cochin Unit, CMFRI campus, \\ Ernakulam - 682018, Kerala, India. \\ ${ }^{2}$ National Bureau of Fish Genetic Resources, Lucknow -226002, India
}

\begin{abstract}
A total of 16 non-O1/ non-O139 Vibrio cholerae isolates were obtained from ornamental fish collected from aquarium traders located in four metro cities of India. All the isolates were confirmed by amplifying the $300 \mathrm{bp}$ fragment in the 16S-23S rRNA intergenic spacer regions. Amplification of $431 \mathrm{bp}$ fragment of gene, which resulted in detectable levels of PCR product, was achieved with a minimum of $8 \mathrm{CFU} / \mathrm{ml}$ of $V$. cholerae. The detection limit for $r t x A$ gene by PCR amplification of genomic DNA was 20 picogram. A $431 \mathrm{bp}$ fragment of the $r t x A$ gene of $V$. cholerae was cloned and sequenced (NCBI accession number EU714289). Nucleotide sequence analysis data of the $r t x A$ gene showed that about $96 \%$ identical to those of $V$. cholerae RTX toxin gene cluster.
\end{abstract}

\section{Introduction}

Vibrio cholerae is an important cause of diarrhea in many parts of Asia and Africa. $V$. cholerae is an autochthonous inhabitant of brackishwater and estuarine systems (Colwell et al. 1977). Toxigenic V. cholerae O1 and V. cholerae O139 are etiological agents of epidemic cholera. However, both $V$. cholerae $\mathrm{O} 1$ strains that do not produce cholera toxin, i.e., that are nontoxigenic, and non-O1/non-O139 strains have also been associated with cholera, gastroenteritis, septicemia, and/or extraintestinal infections (Mukhopadhyay et al. 1995). Conventional methods used to detect and classify choleracausing vibrios isolated from clinical and environmental samples require several days to complete and involve culture in alkaline peptone water, thiosulfate citrate bile sucrose agar, slide agglutination with specific antisera, and assay for production of cholera toxin (Sakazaki 1992). Molecular methods, including PCR and DNA-DNA hybridization performed with probes specific for $V$. cholerae, provide more reliable identification (Chun et al. 1999) but have limitations because of cost and the facilities required for analysis; these limitations are particularly significant for field studies involving large numbers of samples.

\footnotetext{
*Corresponding Author.Tel: 914842395570

Email : rajathanga@yahoo.co.in
} 
Although cholera toxin (CT) is clearly the most important causative factor for cholera, CT deficient isolates of $V$. cholerae also elicit mild to severe diarrhea and other reactogenic symptoms in human, indicating that other toxins are likely to contribute to the pathogenesis of the disease (Coster et al. 1995). A novel toxin in V. cholerae that belongs to the RTX (repeat in toxin) family of toxins, which are generally produced by several pathogenic gram-negative bacteria, was recently discovered (Chow et al. 2001). Lin et al. (1999) proposed that the V. cholerae RTXA (VcRTX-A) toxin, might play a role in the gastrointestinal virulence property of $V$. cholerae. A total of 16 non-O1 and non-O139 V. cholerae were isolated from aquarium fish, koi carp and gold fish in India during the previous study (Swaminathan et al. 2007).

In this study, rapid detection and confirmation of $V$. cholerae non-O1 and nonO139 isolated from koi carp and goldfish by amplification and sequencing of a $431 \mathrm{bp}$ fragment of the rtxA gene of Vibrio cholerae was carried out.

\section{Materials and methods}

\section{Source of the isolates}

A total of $16 \mathrm{~V}$. cholerae non-O1 and non-O139 serogroups isolated from different regions of India were included in our study. All the isolates were obtained from koi Cyprinus carpio koi, goldfish Carassius auratus (L.) during 2004-05. All the isolates were subsequently examined and characterized. The identity of the isolates was confirmed by serotyping at the National Institute for Cholera and Enteric Diseases, Kolkata, India.

\section{Identification of $V$. cholerae by PCR}

Identification and confirmation of isolated $V$. cholerae was done by amplification of a fragment of 16S-23S rRNA intergenic spacer region (ISR) of $V$. cholerae as described by Chun et al. (1999).

\section{Construction of specific PCR primers}

The $r t x A$ sequences of these $V$. cholerae was obtained by accessing the nucleotide sequence database (GenBank accession \# AF119150). The data were examined with multiple alignment analysis (CLUSTAL W), the specific region for bacteria was identified, and the specificity was confirmed by FASTA. Specific PCR primers for identification of $V$. cholerae were designed from the sequence of $r t x A$ using Laser gene 6 software. Primers were tested for specificity among different bacterial isolates. The cross-reactivity of $V$. cholerae rtxA gene primers were checked by NCBI-BLAST and by genomic DNA amplification of other bacteria, i.e. Escherichia coli, Salmonella arizonae, Pseudomonas alcaligenes, Aeromomas hydrophila, Edwardsiella tarda, Staphylococcus aureus and Flavobacterium sp. 


\section{Preparation of PCR samples}

Bacterial pellets were diluted in sterile saline prior to lysis by $10 \mathrm{~min}$ of boiling in a water bath. Bacterial genomic DNA isolation of all $\mathrm{V}$. cholerae was according to Hiney et al. (1992). The nucleic acid preparation was finally suspended in $50 \mu \mathrm{l}$ of TE buffer. The isolated nucleic acid was qualified and quantified at $260 \mathrm{~nm}$ and 260/280 ratios, respectively.

\section{PCR amplification}

The PCR amplification was performed using the primers designed in this study. We used $10 \mathrm{ng}$ of genomic DNA, 50 pmoles of primers, $100 \mu$ moles of each dNTP's and $2 \mathrm{mM}$ of $\mathrm{MgCl}_{2}$. Samples were subjected to 35 cycles of amplification $\left(94^{\circ} \mathrm{C}\right.$ for $2 \mathrm{~min}, 64^{\circ} \mathrm{C}$ for $1 \mathrm{~min}$ and $72^{\circ} \mathrm{C}$ for $3 \mathrm{~min}$ on a Master cycler (Eppendorf). $10 \mu \mathrm{l}$ of the reaction mixture was then analyzed by submarine gel electrophoresis in $1.2 \%$ agarose.

\section{Cloning and Sequencing of 431 bp fragment of V. cholerae rtx A gene}

A fragment of $431 \mathrm{bp}$ of $V$. cholerae rtxA gene was amplified using designed primer. The DNA band of interest was excised and purified from the gel at position 431 bp and was ligated to pCR 2.1 TOPO cloning vector and transformed into DH5 $\alpha$ E. coli strain (Invitrogen). The recombinant clones were confirmed by PCR using designed primer. The two terminal sequences of the cloned genes fragment was determined with the ABI PRISM Dye primer cycle sequencing ready reaction kit and ABI 377 DNA auto sequencing machine by using M13sequence primers.

\section{Sensitivity of the PCR}

For determining the sensitivity of the PCR 10 -fold dilutions ( $8 \times 10^{-5}$ to 8 cells) were tested. When nucleic acids were used, the sensitivity of the PCR was determined by amplifying $5 \mu 1$ of 10 -fold serial dilutions (20ng to $2 \mathrm{pg}$ ). PCR amplification was performed with a DNA thermal cycler as described before.

\section{Results}

Primer pairs was designed on the basis of the nucleotide sequence of the $r t x A$ downloaded from NCBI and used to amplify target sequences in genomic DNA from 16 isolates of $V$. cholerae and yielded a product of the expected $431 \mathrm{bp}$ size for $V$. cholerae (Fig 1). Similar amplification of the expected product size was not observed for the other bacteria viz., Escherichia coli, Salmonella arizonae, Pseudomonas alcaligenes, Aeromomas hydrophila, Edwardsiella tarda, Staphylococcus aureus and Flavobacterium sp when the primer pairs were used. All strains of V. cholerae isolated in our laboratory were confirmed and a PCR amplification product of the expected length (431 bp) was obtained (Fig.1). 

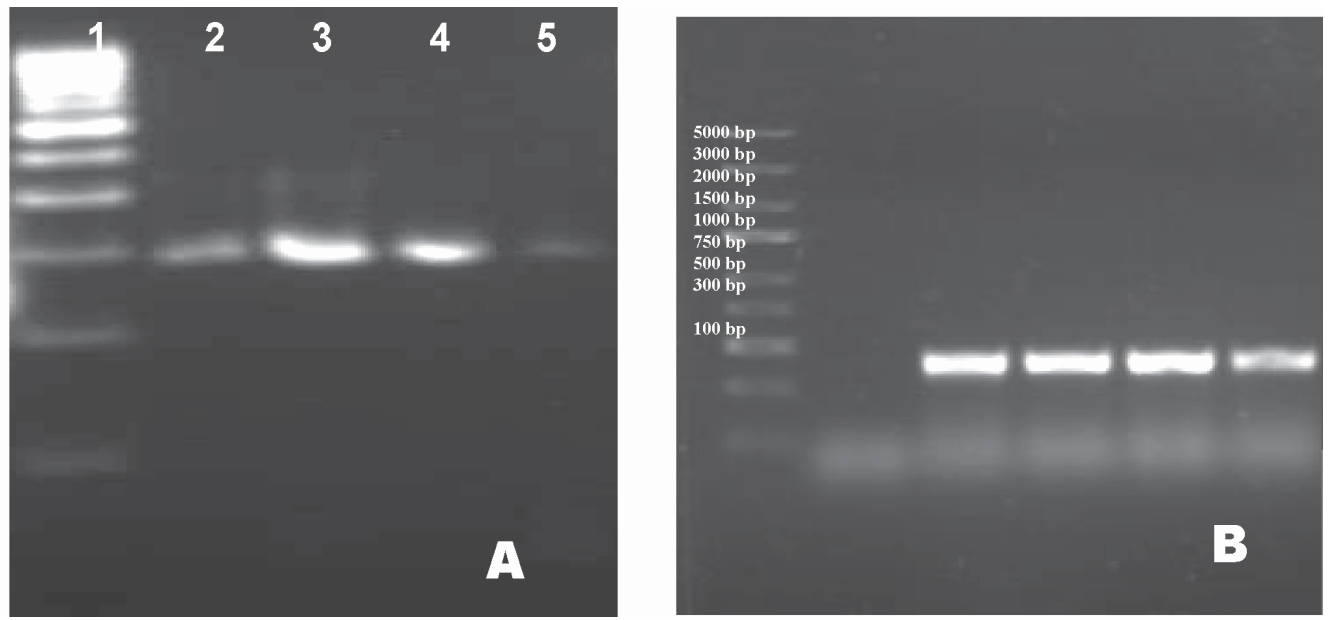

Figure1. Detection of non -O1 and non - O139 Vibrio cholerae by PCR

A- Confirmation of $V$. cholerae by amplification of the fragment of 16S-23S ISR by PCR. Lane 1 - 100bp ladder, lane 2- 5 - 16S-23S ISR (300bp).

B-Detection of $V$. cholerae by amplification of the fragment (417bp). of $r t x A$ gene by PCR.

Lane 1 - Generuler DNA Ladder (Fermentas), Lane 2- Negative control Lane 3 - Positive control

lane 4-6 - Positive test samples

The 431 bp fragment of $r t x A$ of $V$. cholerae was cloned in PCR 2.1 TOPO cloning vector for sequencing. The cloned $431 \mathrm{bp}$ fragment of the $\operatorname{rtxA}$ was sequenced and comparison of this sequence with other sequences from DDBJ/EMBL/Genbank was made. Comparing the $431 \mathrm{bp}$ fragment of the $V$. cholerae isolates $96 \%$ homology with rtxA sequences of $V$. cholerae strains viz., AE003852.1, AF119150.1, was found. The sequence of the $431 \mathrm{bp}$ fragment of $r t x A$ of $V$. cholerae was deposited in the NCBI GenBank (EU714289).

Amplification which resulted in detectable levels of PCR product was achieved when a minimum of $8 \mathrm{CFU} / \mathrm{ml}$ of $V$. cholerae were lysed, on the basis of an average of five repeated testing of viable cells and PCR assays. The minimum amount of purified DNA in the reaction mixture needed to obtain a detectable PCR product was $20 \mathrm{pg}$. The lower limit of detection of $V$. cholerae bacterial cells or isolated DNA by PCR was examined for all the strains of $V$. cholerae. A suspension of cells of the isolates was diluted and processed. A PCR amplification product could not be obtained when a sample with more than $10^{6} \mathrm{CFU}$ was used in the assay, probably because of accumulation of soluble cell products inhibitory to PCR. Isolated DNA from $V$. cholerae was serially diluted in saline and used as a template. The minimum amount of purified DNA in the reaction mixture needed to obtain a detectable PCR product was $20 \mathrm{pg}$.

In the study, we used the PCR technique for the identification of the $r t x A$ genes of $V$. cholerae and the specificity of the primers used here is noteworthy, and can reach high sensitivity. The detection limit for rtxA gene from $V$. cholerae was $20 \mathrm{pg}$. 


\section{Discussion}

This study was undertaken to explore the possibility of contamination of $V$. cholerae serogroups $\mathrm{O} 1$ and $\mathrm{O} 139$, the most important causative organisms for cholera and also potential public health importance, by isolating these organisms from body surface, gill and intestine of common ornamental fishes. V. cholerae is often transmitted by water but fish or fish products that have been in contact with contaminated water or faeces from infected persons also frequently serve as a source of infection (Colwell et al. 1977). V. cholerae $\mathrm{O} 1$ or $\mathrm{O} 139$ were not isolated from body surface swabs, gills and intestine of these common table fishes. Dalsgaard et al. (1995) isolated $143 \mathrm{~V}$. cholerae non-O1 strains from shrimp farms in Thailand, and characterized and grouped by ribotyping. All the 16 isolates of $V$. cholerae isolated in our laboratory were confirmed and a PCR amplification product of the expected length (431 bp) of $r t x A$ gene was obtained. Nonepidemic V. cholerae non-O1 serogroup strains, which cause only sporadic, milder cases of diarrhea, do secrete the RTX cytotoxins but do not secrete CT (Chow et al. 2001). The sequence of the $431 \mathrm{bp}$ fragment of the $r t x A$ gene had showed $96 \%$ homology with the other rtxA gene sequences of the V. cholerae, viz., AE003852, AF119150.

Non-O1/ non-O139 V. cholerae strains can no longer be ignored. The rationale for continuous monitoring is based on the emergence of serogroup O139 (Bengal) in Bangladesh (CT positive) and Argentina (CT negative), each of which clearly evolved independently. The sixth pandemic, the seventh pandemic, and U.S. Gulf Coast isolates represent three different clones, each independently evolved from environmental nonO1 V. cholerae isolates (Karaolis et al. 1995). Finally, the emergence of a new clone of the V. cholerae O1 El Tor in Calcutta, India (Sharma et al. 1997) has been reported. The possibility exists that those additional new strains of toxigenic V. cholerae with epidemic potential may emerge in the future. While CT is a principal virulence factor for $V$. cholerae, the contribution of the RTX toxins to its pathogenesis requires further investigation.

In previous study it was described that the rtx gene was absent only from the $V$. cholerae classical $\mathrm{O} 1$ serogroup strain, which has greater epidemic potential than strains of the other serogroups, despite its displacement by the El Tor biotype since the seventh pandemic (Chow et al. 2001). Therefore, nonepidemic V. cholerae non-O1 serogroup strains, which cause only sporadic, milder cases of diarrhea, does secrete the RTX cytotoxins but do not secrete CT. Further investigation is required to determine the role of RTX in the pathogenicity of non-O1 /non-O139 V. cholerae.

\section{Conclusion}

The $431 \mathrm{bp}$ fragment of $r t x A$ of $V$. cholerae was amplified by the primer designed and the PCR product was cloned in pCR 2.1 TOPO cloning vector for sequencing. The cloned $431 \mathrm{bp}$ fragment of the $r t x A$ was sequenced and comparison of this sequence with other sequences from DDBJ/EMBL/Genbank was made. The sequence of the 
431 bp fragment of rtxA of $V$. cholerae was deposited in the NCBI GenBank (EU714289). The sensitivity and specificity of the primer designed to detect the rtxA gene fragment of $V$. cholerae were checked. The primer could identify $8 \mathrm{CFU} / \mathrm{mL} V$. cholerae and $20 \mathrm{pg}$ of purified DNA of $V$. cholerae.

\section{Acknowledgement}

The authors are grateful to Dr S. Ayyapan,, DDG (Fy), ICAR, New Delhi for the encouragement.

\section{Reference}

Chow, K.H., T.K. Ng, K.Y Yuen and W.C. Yam 2001. Detection of RTX Toxin Gene in Vibrio cholerae by PCR. Journal of Clinical Microbiology 39 (7): 2594-2597.

Chun, J., A. Huo and R. Colwell. 1999. Analysis of 16S-23S rRNA intergenic spacer regions of Vibrio cholerae and Vibrio mimicus. Applied Environmental Microbiology 65: 2202-08.

Colwell, R.R., J.B Kaper and S. W. Joseph. 1977. Vibrio cholerae, Vibrio parahaemolyticus and other Vibrios: occurrence and distribution in Chesapeake Bay. Science 198: 394-396.

Coster, T. S., K. P. Killeen, M. K. Waldor, D.T. Beattie, D. R. Spriggs, J.R. Kenner, A. Trofa, J.C. Sadoff, J. J. Mekalanos and D. N. Taylor. 1995. Safety, immunogenicity, and efficacy of live attenuated Vibrio cholerae O139 vaccine prototype. Lancet 15: 949-52.

Dalsgaard, A., P. Echeverria, J. L. Larsen, R. Siebeling, O. Serichantalergs and H.H. Huss. 1995 Application of Ribotyping for Differentiating Vibrio cholerae Non-O1 Isolated from Shrimp Farms in Thailand. Applied Environmental Microbiology 61(1): 245-251.

Hiney, M., M.T. Dawson, D.M. Heery, P.R. Smith, F. Gannon and R. Powell 1992. DNA probe for Aeromonas salmonicida. Applied Environmental Microbiology 58(3) : 1039-1042.

Karaolis, D. K. R., R. Lan, and P. R. Reeves. 1995. The sixth and seventh cholera pandemic are due to independent clones separately derived from environmental, non-toxigenic, non-O1 Vibrio cholerae. Journal of Bacteriology 177: 3193-3198.

Lin, W., K.J. Fullner, R. Clayton, J.A. Sexton, M.B. Rogers, K.E. Calia, S.B. Calderwood, C. Fraser and J.J. Mekalanos. 1999. Identification of a Vibrio cholerae RTX toxin gene cluster that is tightly linked to the cholera toxin prophage. Proceedings of National Academy of Science 96: 1071-76.

Mukhopadhyay, A. K., P. K. Saha, S. Garg, S. K. Bhattacharya, T. Shimada,T. Takeda, Y. Takeda and G. B. Nair. 1995. Distribution and virulence of Vibrio cholerae belonging to serogroups other than O1 and O139: a nation survey. Epidemiology and Infection 114: 65-70.

Sakazaki, R. 1992. Bacteriology of Vibrio and related organisms, In: Cholera. (Ed., D. Barua and W. B. Greenough III), pp. 37-55. Plenum Medical Book Company, New York, N.Y.

Sharma, C., G. B. Nair, A. K. Mukhopadhyay, S. K. Bhattacharya, R. K. Ghosh, and A. Ghosh. 1997. Molecular characterization of Vibrio cholerae O1 biotype El Tor strains isolates between 1992 and 1995 in Calcutta, India: evidence for the emergence of a new clone of the El Tor biotype. Journal of Infectious Diseases 175: 1134-1141.

Swaminathan, T. R., G, Rathore, N. Sood and W.S. Lakra. 2007. Vibrio cholerae non-O1 and non-O139 serogroups isolated from ornamental fish in India. Indian Veterinary Journal 84: 1023-25. 